Nurul Fatahah Asyqin Zainal, Jean Marc Saiter, Suhaila Idayu Abdul Halim, Romain Lucas and Chin Han Chan*

\title{
Thermal analysis: basic concept of differential scanning calorimetry and thermogravimetry for beginners
}

https://doi.org/10.1515/cti-2020-0010

Received May 27, 2020; accepted November 11, 2020; published online November 26, 2020

\begin{abstract}
We present an overview for the basic fundamental of thermal analysis, which is applicable for educational purposes, especially for lecturers at the universities, who may refer to the articles as the references to "teach" or to "lecture" to final year project students or young researchers who are working on their postgraduate projects. Description of basic instrumentation [i.e. differential scanning calorimetry (DSC) and thermogravimetry (TGA)] covers from what we should know about the instrument, calibration, baseline and samples' signal. We also provide the step-by-step guides for the estimation of the glass transition temperature after DSC as well as examples and exercises are included, which are applicable for teaching activities. Glass transition temperature is an important property for commercial application of a polymeric material, e.g. packaging, automotive, etc. TGA is also highlighted where the analysis gives important thermal degradation information of a material to avoid sample decomposition during the DSC measurement. The step-by-step guides of the estimation of the activation energy after TGA based on Hoffman's Arrhenius-like relationship are also provided.
\end{abstract}

Keywords: decomposition temperature; differential scanning calorimetry; glass transition temperature; thermal properties; thermogravimetry.

\section{Introduction}

Thermal analysis consists of techniques used to determine the physical or chemical properties of a substance when it is heated, cooled, or held at a constant temperature. These techniques were first introduced back in 1887 by Henry Le Chatelier, in which is considered as the dawn of present-day thermal analysis. Nevertheless, since the end of the Second World War, it was not easy to perform such experiments. However, the rapid

Note: Part of the content of this article is extracted from one of the instructor's notes based on the short course presented at the 25th POLYCHAR 2017 World Forum on Advanced Materials, Kuala Lumpur, Malaysia, October 9-13, 2017. The power point slides can be accessed via https://iupac.org/wp-content/uploads/2017/12/IUPAC_PolymEdu_Shortcourse_2ppt_JeanMarcSaiter.pdf and the

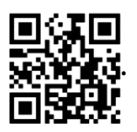

*Corresponding author: Chin Han Chan, Faculty of Applied Sciences, Universiti Teknologi MARA, 40450 Shah Alam, Selangor, Malaysia, E-mail: cchan_25@yahoo.com.sg. https://orcid.org/0000-0003-0990-0155

Nurul Fatahah Asyqin Zainal, Centre of Foundation Studies, Universiti Teknologi MARA, Cawangan Selangor, Kampus Dengkil, 43800 Dengkil, Selangor, Malaysia

Jean Marc Saiter, Faculté des Sciences, Laboratoire Sciences et Méthodes Séparatives, Université de Rouen Normandie, 76821 Rouen, Mont-Saint-Aignan Cedex, France; Tweed Lab, Onyx Developpment, Groupe-Nutriset, Hameau du Bois Ricard, 76770 Malaunay, France

Suhaila Idayu Abdul Halim, Faculty of Applied Sciences, Universiti Teknologi MARA, 40450 Shah Alam, Selangor, Malaysia Romain Lucas, IRCER, UMR CNRS 7315, Université de Limoges, F-87068 Limoges Cedex, France

Ә Open Access. ( 2020 Nurul Fatahah Asyqin Zainal et al., published by De Gruyter. $($ (c) BY This work is licensed under the Creative Commons Attribution 4.0 International License. 
growth of the electronic tools and computer devices observed for the last 30 years, making it relatively easy to find thermal analyzers in an analytical laboratory. The modern thermal analyzers are apparently very easy to be used and it is common to see someone performs a measurement without a clear objective. When questions are asked: why did you perform this differential scanning calorimetry scan? Why did you use this protocol? The answer is: "this is only to see, and I use the standard protocol of the lab". That is an erroneous statement and it reflects the negligent attitude. Looking at the scientific literature, it is possible to find many books or articles, which focus on thermal analysis methods and the instruments. Nevertheless, looking at many data published in the literature using these techniques, it appears that many mistakes are still made. Hence, the purpose of this paper is to show what are the common mistakes and how to do a good measurement rather than to explain what we can do for the data analysis. We firmly believe that a correct data discussion requires at first a correct data acquisition.

Despite of numerous books and articles published on thermal analysis method (Hatakeyama \& Quinn, 1999; Loft, 1975; Saiter, Negahban, Claro, Delabare, \& Garda, 2008; Schick, 2009; Wunderlich, 1994; Wunderlich, 2006; Wunderlich, 2007), these publications may be too difficult for course instructors or beginners to follow for their first attempt to the subject or experiment.

Thus, this article may serve as an alternative reference for the mentioned readers. In this article, we will highlight the basic instrumentation of differential scanning calorimetry (DSC) and thermogravimetric (TGA), as well as the step-by-step guides for the estimation of the glass transition temperature $\left(T_{\mathrm{g}}\right)$ after DSC. The examples and exercises for the $T_{\mathrm{g}}$ estimation are also provided. Additionally, the step-by-step guides for the determination of the degradation temperature and the activation energy $\left(E_{\mathrm{a}}\right)$ of the degradation are provided. The main objective of this article is to provide a basic fundamental of thermal analysis for beginners which is rather easy to follow and can be utilized for educational purposes. TGA is an important analysis which needs to be performed before the DSC measurement in order to avoid any sample degradation during the DSC measurement. Examples of DSC and TGA instruments are presented in Figure 1.

For supplementary reading materials, we have listed the related journals and books in Annexe 1. There are also many thermal analysis conferences organized by local and/or international organization each year, and we propose to look for more information from the International Confederation for Thermal Analysis and Calorimetry (ICTAC) website (http://www.ictac.org/).

\section{General consideration}

Thermal analysis is the evolution of a physical property of "something" when the temperature changes according to a given time/temperature control. The values of two physical quantities must be known, which means that the equipment consists of at least two sensors, each of them require a calibration procedure. For instance, the determination of the change in the sample's mass when the temperature is changed will involve two sensors, namely balance and thermometer. Each sensor has its own accuracy, sensitivity, domain of use, etc., which will give the limit of the measurements in terms of the expanded measurement uncertainty and the acceptable number of decimal points of the data. This consideration leads to:

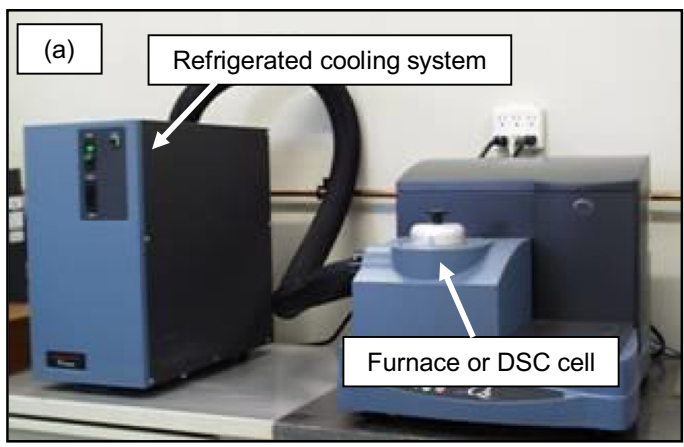

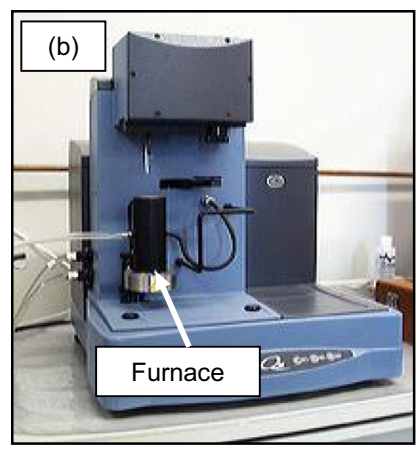

Figure 1: Instruments of (a) differential scanning calorimetry and (b) thermogravimetry analysis (Thermal Analysis, n.d.a,b). 


\section{Rule number 1}

\section{Before using any equipment, we must know its real performances.}

Name of the equipment

Nature of the sensors, what is exactly determined, [volume change $(\Delta V)$, temperature change $(\Delta T)$, pressure change $(\Delta P)$, mass change $(\Delta m), \ldots$ ]

Method of measurements

Expected measurement accuracy

Domain of temperature able to be scanned

Controlled heating rates available

Controlled cooling rate available (cooling rate of many instrument is not under control)

Baseline linearity and baseline quality

Purge gas, nature, flux, how that is under control.

What kind of samples are accepted by the equipment (solid, bulk, powder, liquid...)

The second point relates to the sample. The expected properties of the sample must be known. Preliminary studies based on published papers on the material or/and similar materials must be done. We can now enunciate:

\section{Rule number 2}

\section{Before using any equipment, we must know what we want to know.}

The limit of temperature that a sample can reach before it is thermally degraded

The melting temperature and the associated enthalpy

A glass transition temperature

A Curie temperature

A secondary relaxation

A value of heat capacity

A kinetic of degradation, of crystallization, of curing...

The third point concerns the calibration procedure. As we have two sensors to calibrate, we must have a procedure for each of them. When the temperature changes, we have to consider the problem of heat transfer i.e. convection, conduction and radiation processes. These phenomena are affected by the geometry and the shape of the oven and so on. In other words, the effect of the heating rate on the heat transfer in the oven is fundamental and as a consequence, a calibration procedure will be valuable only for one given heating rate. If the heating rate is changed in the protocol, a new calibration must be done.

\section{Exercise 1}

A good exercise is to use the melting signal of a pure element determined by DSC. For instance, indium. The protocol is suggested to be:

Insert $5 \mathrm{mg}$ of indium in a DSC pan

Run from 100 to $200^{\circ} \mathrm{C}$ with a heating rate of $10^{\circ} \mathrm{C} \mathrm{min}^{-1}$ (called $\mathrm{C}_{0}$ )

Go back to $100^{\circ} \mathrm{C}$ with a cooling rate of $10^{\circ} \mathrm{C} / \mathrm{min}$

Run from 100 to $200^{\circ} \mathrm{C}$ with a heating rate of $20^{\circ} \mathrm{C} \mathrm{min}{ }^{-1}$ (called $\mathrm{C}_{1}$ )

Go back to $100{ }^{\circ} \mathrm{C}$ with a cooling rate of $10{ }^{\circ} \mathrm{C} / \mathrm{min}$

Run from 100 to $200^{\circ} \mathrm{C}$ with a heating rate of $100{ }^{\circ} \mathrm{C} \mathrm{min}^{-1}$ (called $\mathrm{C}_{2}$ )

Go back to $100{ }^{\circ} \mathrm{C}$ with a cooling rate of $10^{\circ} \mathrm{C} / \mathrm{min}$

Run from 100 to $200{ }^{\circ} \mathrm{C}$ with a heating rate of $1{ }^{\circ} \mathrm{C} \mathrm{min}^{-1}$ (called $\mathrm{C}_{3}$ )

Go back to $100{ }^{\circ} \mathrm{C}$ with a cooling rate of $10^{\circ} \mathrm{C} / \mathrm{min}$

Run from 100 to $200{ }^{\circ} \mathrm{C}$ with a heating rate of $10^{\circ} \mathrm{C} \min ^{-1}$ (called $\mathrm{C}_{4}$ )

Go back to room temperature. 

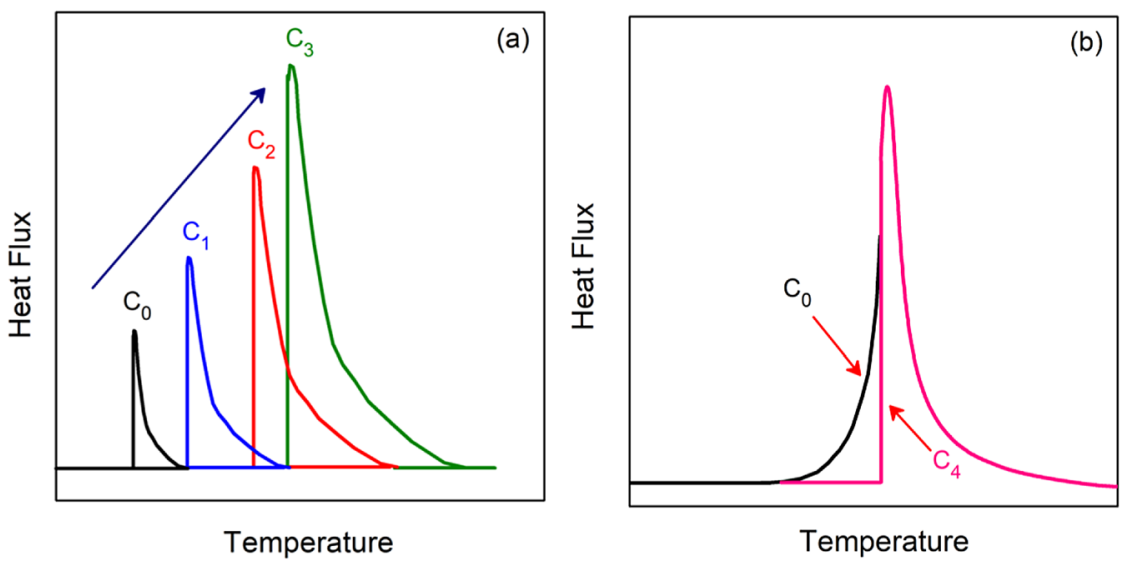

Figure 2: (a) DSC signals of the fusion of a pure element when scanned from low (spectrum $\mathrm{C}_{0}$ ) to high heating rate (spectrum $\mathrm{C}_{3}$ ) and (b) comparison of the effects of different successive melting/crystallization cycles on the shape of a fusion signal for a pure element.

Finally, remove the indium sample and keep it for the next calibration procedure. Now by plotting all the signals (except signal $\mathrm{C}_{4}$ ) on the same graph, followed by another graph for signal $\mathrm{C}_{0}$ and $\mathrm{C}_{4}$ together, we must get something as shown in Figure 2.

When the heating rate increases, the comparison of the signals $\mathrm{C}_{0}-\mathrm{C}_{3}$ show:

A shift to the higher temperatures of the fusion

The magnitude of the signal increases

The width of the signal increases

Nevertheless, by definition the fusion of a pure element does not depend on the heating rate. The energy necessary to melt the indium metal is the same for any heating rate used (Wendlandt, 1986; Wunderlich, 1994). Instead, the heating rate is affecting the instrument resolution and sensitivity. Thus, this observation is not the signature of the material but the signature of the equipment [c.f Figure 2(b)]. We can now write the:

\section{Rule number 3}

A calibration procedure is valuable only for one given heating rate, if the heating rate is changed, a new calibration procedure must be done.

The fourth rule is also linked to the calibration procedure. As we need to calibrate two sensors in a temperature domain, it is important to remember that what is true for one temperature is not necessary true for another one. For instance, to calibrate a temperature in a calorimeter, we may use the fusion of indium. We will obtain the temperature shift in order to know the true temperature. For example, the temperature of fusion of indium is $156.6^{\circ} \mathrm{C}$ and the measurement with a given heating rate is $157.7^{\circ} \mathrm{C}$. We can deduce that we have to make a correction of $1.1^{\circ} \mathrm{C}$ to get a good result. Nevertheless, that is true only for the temperature domain close to the fusion temperature. We may not know if the same temperature shift can be used at $20^{\circ} \mathrm{C}$. That is graphically explained in Figure 3.

\section{Rule number 4}

We need at least two standard references in the temperature domain investigated to perform a calibration.

One equipment may have the possibility to get simultaneously different quantities, for example heat flux, instantaneous sample's mass and infrared (IR) spectra. However, this kind of equipment will not be performant for all the quantities measured. Each sensor must be independently calibrated. So, the common idea that we could win time is not true. That leads to:

\section{Rule number 5}

The more sensors we have, the more complex is the equipment and generally less sensibility each sensor will have.

Rule 1 - Rule 5 explain on the important steps for DSC users to apply before any measurement of sample is done. Apart from the instrumentation, estimation of the correct data is also crucial in order to obtain a precise and reproducible data. 

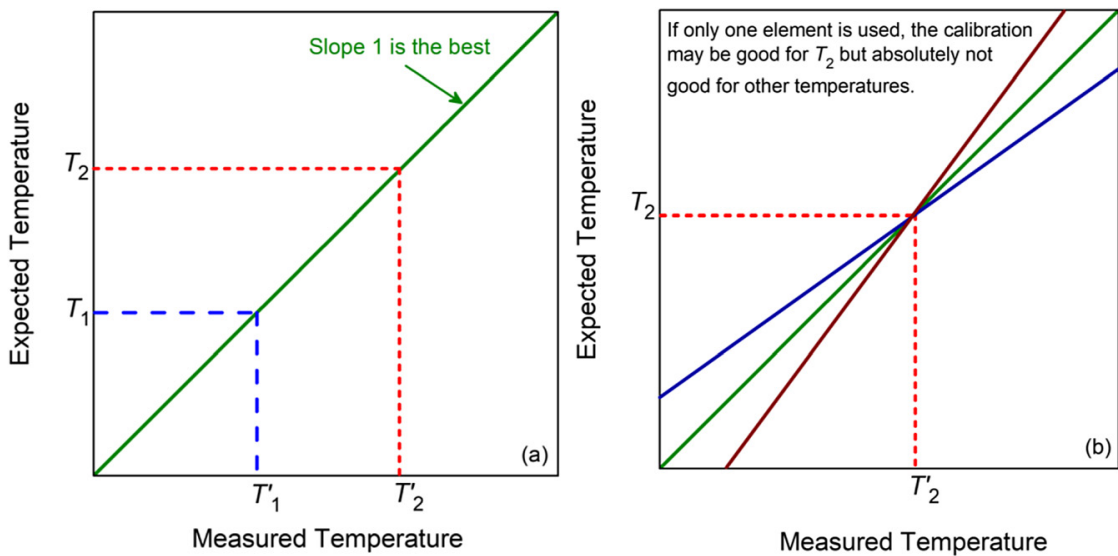

Figure 3: (a) One-standard calibration (b) at least two standards are needed to perform a good calibration.

\section{The glass transition}

Glass transition is one of the important properties of polymers, which describes the temperature region where the mechanical properties change from hard and brittle to soft and rubbery. This property is crucial in determining which polymers are suitable for particular end-use in any application. Polymers are classified as thermoplastic, thermosets and elastomer which consist of amorphous structure which make most polymers exhibit $T_{\mathrm{g}}$. Figure 4 shows the classification of polymers which are classified as thermoplastic and thermosets. Both thermoplastic and thermoset polymers exhibit $T_{\mathrm{g}}$ which shows a transition from hard to rubber-like, marking a region of dramatic changes in the physical properties, such as elasticity and hardness. Hence, in this initiative, a good practice on the estimation of $T_{\mathrm{g}}$ will be highlighted. Three supplementary files (i.e. $\mathbf{S 1}$-Notes for Course Instructor, S2-Examples to Estimate $T_{\mathrm{g}}$ and $\mathbf{S 3}$-Exercise for Students) are provided. S1 describes the step-by-step guide in estimating the $T_{\mathrm{g}}$ using Moynihan's approach. $\mathbf{S 2}$ provides the examples of estimation of $T_{\mathrm{g}}$ with and without Moynihan's approach using manual graphical method and $\mathbf{S} \mathbf{3}$ provides four exercises to estimate the $T_{\mathrm{g}}$ using manual graphical method.

A good estimation of $T_{\mathrm{g}}$ may yield a $T_{\mathrm{g}}$ value that differs by $3-4^{\circ} \mathrm{C}$ as compared to the imprecise estimation technique. For example, in a system of epoxidized natural rubber with $50 \mathrm{~mol} \%$ epoxidation (ENR-50), a good estimation may give a $T_{\mathrm{g}}=-19^{\circ} \mathrm{C}$ (Halim, Chan, \& Kammer, 2019), and conversely, an imprecise estimation will normally give $T_{\mathrm{g}}=-15^{\circ} \mathrm{C}$. This is an example of common mistakes which can be observed in the literature. Consequently, the discussion based on this imprecise estimation may not be correct. Example of a good and

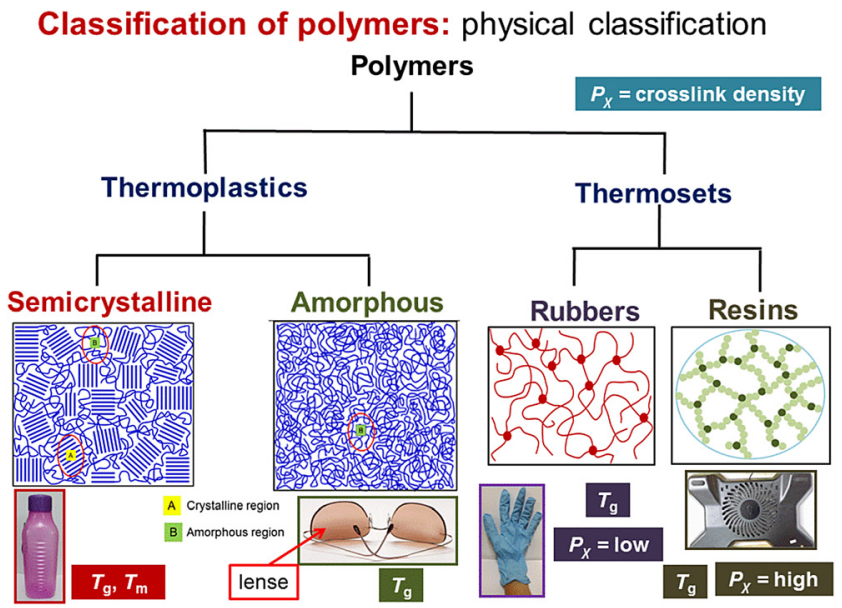

Figure 4: Classification of polymers. 

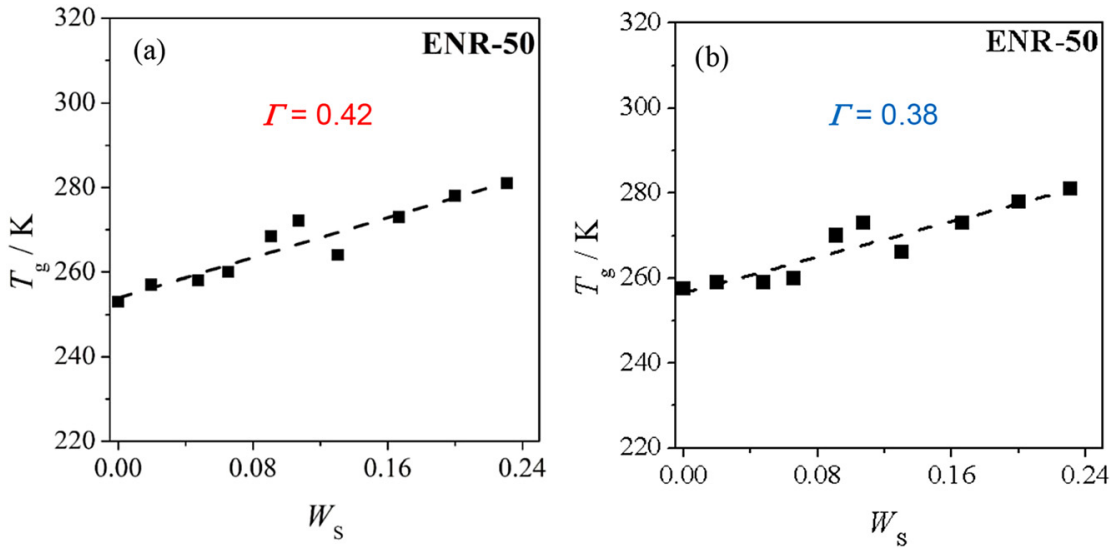

Figure 5: (a) Good and (b) imprecise estimation of $T_{\mathrm{g}}$ for ENR-50 as a function of mass fraction of salt. Dashed lines are the best fit regression of the experimental data with regression coefficient, $r^{2}=0.90$ and $r^{2}=0.87$ for good and imprecise estimation of $T_{\mathrm{g}}$, respectively.

imprecise estimation of $T_{\mathrm{g}}$ are presented in Figure 5. In this example, further analysis of the $T_{\mathrm{g}}$ values were done based on linear regression analysis as written in Eq. (1);

$$
\frac{T_{\mathrm{g}}}{T_{\mathrm{g}}^{o}}=1+\Gamma W_{\mathrm{S}}
$$

where $T_{\mathrm{g}}^{o}$ is the glass transition temperature of neat polymer, $\Gamma$ is the slope of the linear curve and $W_{S}$ is the mass fraction of salt (Halim et al., 2019). As presented in Figure 5(a) and (b), good and imprecise estimation of $T_{\mathrm{g}}$ yield different values of $\Gamma$. It gives $\Gamma=0.42$ and $\Gamma=0.38$ for good and imprecise estimation of $T_{\mathrm{g}}$, respectively, where the higher $\Gamma$ value indicates higher freezing in of polymer chain's degree of freedom with addition of inorganic salt to the ENR-50. This may suggest that the estimation of $T_{\mathrm{g}}$ is a crucial part before any data interpretation can be made.

This approach that we proposed is easy to be followed for new users. A group of 39 new users of DSC were presented the step-by-step guides on estimation of $T_{\mathrm{g}}$ (refer to S2) and subsequently they tried to estimate the $T_{\mathrm{g}}$ using graphical method as in S3. The $T_{\mathrm{g}}$ values reported for poly(ethylene oxide) (PEO) are PEO $=-52.0 \pm 0.6^{\circ} \mathrm{C}$ and ENR- $25=-45.0 \pm 0.3^{\circ} \mathrm{C}$. Consequently, as a rule of thumb, the reported $T_{\mathrm{g}}$ values of PEO and ENR should be -52 and $-45^{\circ} \mathrm{C}$, respectively. The guides enable the users to understand the basic working principles for estimation of $T_{\mathrm{g}}$ when they rely on the thermal analysis softwares in subsequent attempt.

We note here, different thermal analysis softwares may have different mathematical algorithms for the estimation of $T_{\mathrm{g}}$. With the basic understanding as presented as in $\mathbf{S 2}$, the users may choose the suitable mathematical algorithm for data extraction based on the "shape" of the glass transition of the DSC scan. Thus, this article may serve as a suitable teaching material for teachers and instructors.

\section{Thermogravimetry}

In this section, thermogravimetry will be explained. Thermogravimetric analysis is an important analysis that should be carried out before DSC measurement. This is because, no mass loss or sample decomposition should happen in the DSC. Bad signals as well as damage to the instrument will occur. Thermogravimetry is the determination of the change in the sample mass during heating or time for a given temperature (c.f Figure 6).

Thus, we need a balance and the best one is the famous Roberval one as shown in Figure 7. In this system the mass is not directly determined, only the mass added to keep the equilibrium is determined. This is an analogue to a constant zero measurement method used in a Wheatstone bridge. 


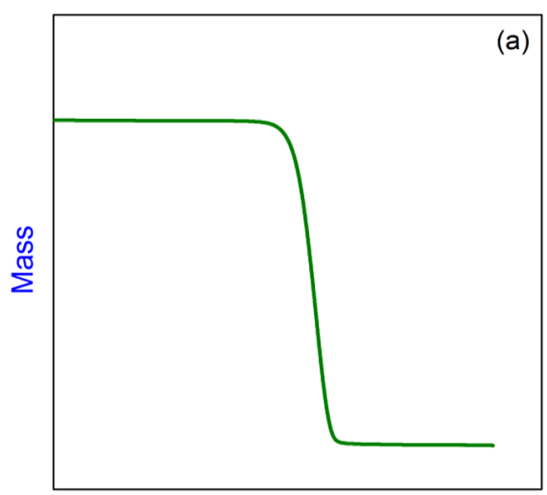

Temperature

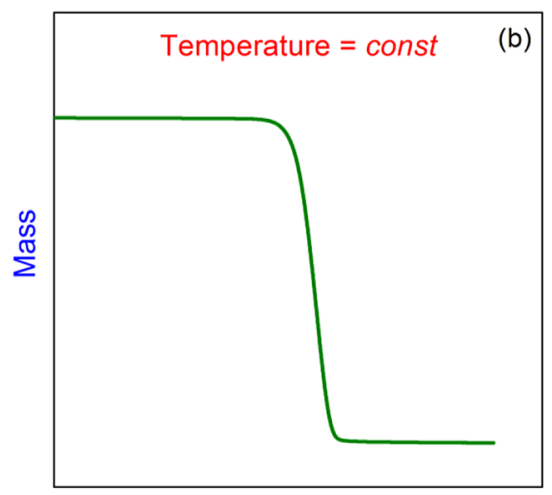

Time
Figure 6: Two ways to perform a thermogravimetric measurement with variation of (a) temperature and (b) time.

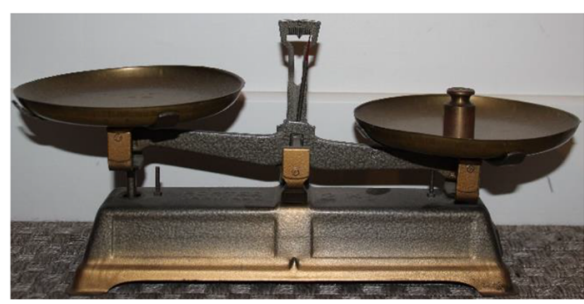

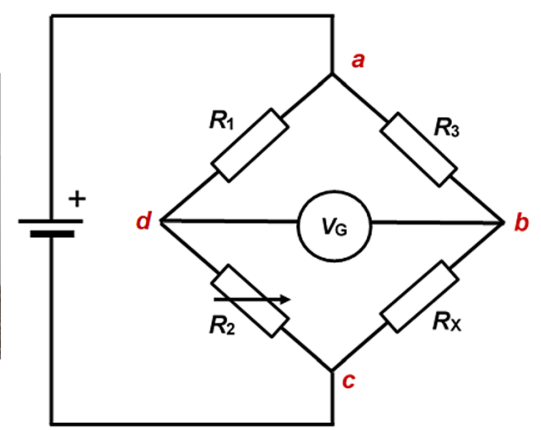

Figure 7: Roberval balance (left) and Wheatstone bridge circuit diagram (right) which has four arms connected at points $a, b$, $c$ and $d, R_{X}$ is the unknown resistance, $R_{1}, R_{2}$ and $R_{3}$ are known resistance where $R_{2}$ is adjustable and $V_{G}$ is the measured voltage.

Different configurations of balance are shown in Figure 8, but whatever the shape of the oven, a good thermo-balance must be able:

1) To detect a mass variation of one micro gram in the full domain of temperature available.

2) To scan a domain of temperature from $10^{\circ} \mathrm{C}$ to $1500^{\circ} \mathrm{C} .1000^{\circ} \mathrm{C}$ can be enough for organic components and the lower temperature is required if the evaporation of water needs to be evaluated. This low temperature is also needed because the time lag between the temperature for which the measurement begins and the temperature for which the stability of the balance is obtained depends upon the heating rate and may need a long time for the water evaporation process to occur.

3) To control the nature and the flux of the gas (oxygen, air, nitrogen, argon) during experiment.

Assuming a constant pressure during all the experimental duration, equilibrium is obtained when the summation of all the forces applied is nil as written in Eq. (2).

$$
\sum \vec{F}=0
$$

If we applied this very simple relationship to our system, we have Eq. (3)

$$
\vec{P}_{\mathrm{a}}+\vec{P}_{\mathrm{e}}+\vec{P}=\overrightarrow{0}
$$

where $P$ is the instantaneous force of gravity, $P_{\mathrm{a}}$ is the Archimedes reaction according to the fact that the system is in a fluid ambiance and has achieved its hydrostatic equilibrium, where the buoyant force is equal to its weight, and $P_{\mathrm{e}}$ is the force of gravity measured to get the equilibrium as shown in Figure 9.

This is the value of $m(T)$ that we want to know, and this one is determined by Eq. (4)

$$
m(T)=\rho(T) V+m_{\mathrm{e}}
$$

thus, we need to know the quantity $\rho(T) V$ or at least its effect on the accuracy of our measurement. One way to observe the effect of Archimedes reaction consists to perform a measurement with an inert sample or with no 


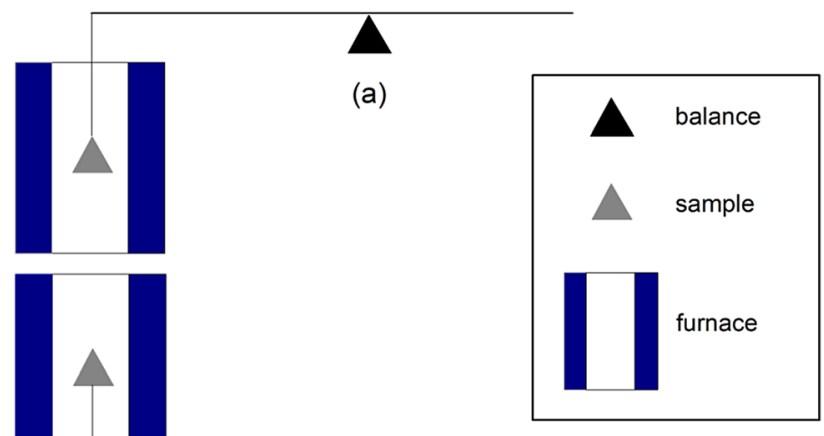

(b)

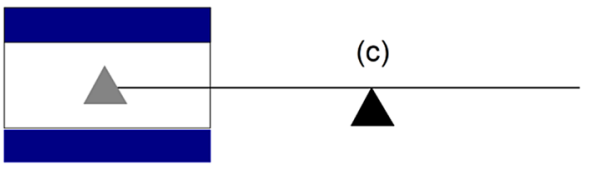

Figure 8: Schematic of the position of the furnace with respect to the balance

(a) below the balance (b) above the balance and

(c) beside the balance.

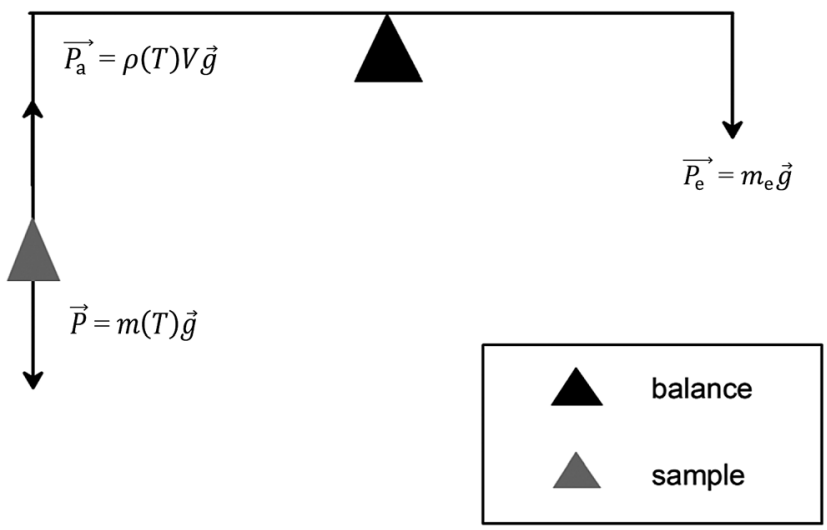

Figure 9: Forces engaged to get the equilibrium of the balance.

sample, which is equivalent to determine the behavior and quality of the base line of the thermogravimetry. As Figure 10 shows, the baseline obtained can be different from the expected one because in addition to the Archimedes effect, the sensors will also give its own contribution (there is no reason that the sensor exhibits identical accuracy, identical linearity, for all the temperatures scanned).

The first step using a thermobalance is to know what the baseline is, when the experimental conditions are changed. For that, we propose Exercise 2.

\section{Exercise 2}

A good training is to make different baselines by changing the experimental conditions, for example;

Base line one $\left(\mathrm{BL}_{1}\right)$

Nitrogen gas with a low value of the flux $\left(\mathrm{F}_{1}\right)$

Empty oven

Heating rate of $10^{\circ} \mathrm{C} \mathrm{min}^{-1}$

Domain of temperature scan from 50 to $800^{\circ} \mathrm{C}$ (or $1000^{\circ} \mathrm{C}$ if possible)

Base line two $\left(\mathrm{BL}_{2}\right)$

Nitrogen gas with a low value of the flux $\left(F_{1}\right)$

Empty oven

Heating rate of $50{ }^{\circ} \mathrm{C} \mathrm{min}^{-1}$

Domain of temperature scan from 50 to $800{ }^{\circ} \mathrm{C}$ (or $1000^{\circ} \mathrm{C}$ if possible) 


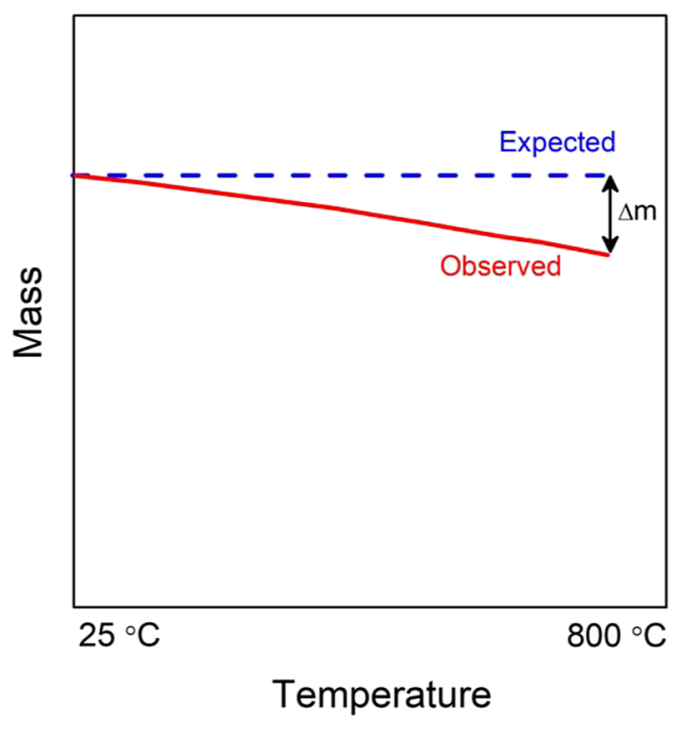

Figure 10: Example of a baseline obtained during a thermogravimetric measurement.

Base line three $\left(\mathrm{BL}_{3}\right)$

Nitrogen gas with a high value of the flux $\left(\mathrm{F}_{2}\right)$

Empty oven

Heating rate of $10{ }^{\circ} \mathrm{C} \mathrm{min}-1$

Domain of temperature scan from 50 to $800^{\circ} \mathrm{C}$ (or $1000^{\circ} \mathrm{C}$ if possible)

Base line four $\left(\mathrm{BL}_{4}\right)$

Nitrogen gas with a high value of the flux $\left(\mathrm{F}_{2}\right)$

Empty oven

Heating rate of $50{ }^{\circ} \mathrm{C} \min ^{-1}$

Domain of temperature scan from 50 to $800^{\circ} \mathrm{C}$ (or $1000^{\circ} \mathrm{C}$ if possible)

The next step is to superimpose these curves and to analyze the differences observed and conclude the effect of the heating rate and gas flux. Due to the different of the geometry and sensors of the equipment, the results obtained can be different. Nevertheless, by this way it is possible for each apparatus to determine what are the optimized values for the heating rate and the gas flux. We may now write:

\section{Rule number 6}

It is of prime importance to make a baseline and to analyze its shape before any new series of measurement with the same experimental conditions that we will use for the sample data acquisition.

After the quality of the baseline is determined, the calibration procedure has to be performed. As previously explained, the calibration procedure requires the true mass and the true temperature. Hence, we need to calibrate the two sensors.

For the mass sensor, it is relatively easy to get the reference of the mass as it is generally given by the balance supplier. Conversely, it is more difficult for temperature sensor as the standard material with a degradation process (mass loss) occurring exactly at one given temperature does not exist. A procedure using magnetic materials with different Curie temperatures may be used, but this method requires specific equipment and is difficult to bring into play. An alternative method is to get a certificate of calibration from equipment supplier, then choose a material for instance a poly(vinylchloride) (PVC) (plastic which exhibits a very simple signal of degradation which can be easily quantified, if of course the sample composition is well known), similarly, cellulosic materials can be used. The only problem is to have enough amount of sample to be able to recalibrate during many years and to be sure that the secondary reference is stable enough during storage. The signals expected on a thermogravimetric curve are summarized in Figure 11. 


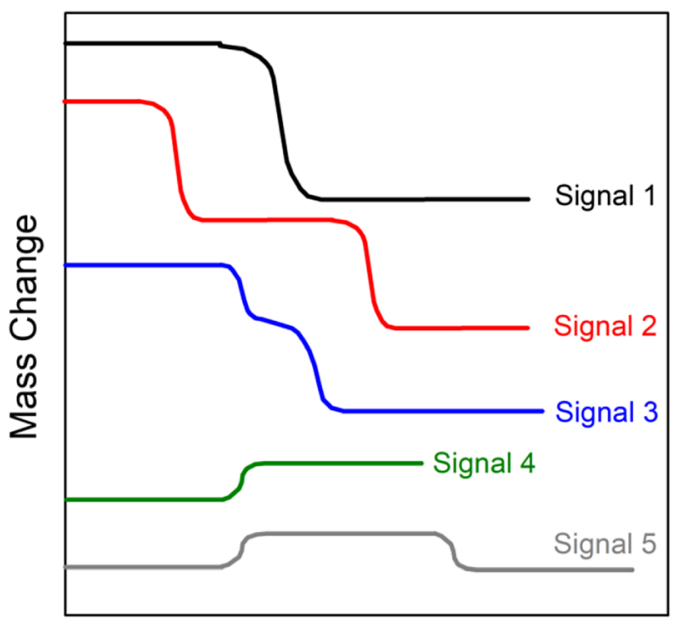

Temperature

Figure 11: Five different themogravimetric curves.

Signal 1 - single decomposition process

Signal 2 - multi decomposition step process

Signal 3 - multi more or less superimposed decomposition step process

Signal 4 - an absorption process

Signal 5 - an absorption followed by a desorption process

Table 1: Quantities estimated from a thermogravimetric curve with a single decomposition process.

\begin{tabular}{llllllll}
\hline $\boldsymbol{m}_{\mathbf{i}}$ & $\boldsymbol{m}_{\mathrm{f}}$ & $\boldsymbol{\Delta}$ & $\boldsymbol{T}_{\mathbf{1}}$ & $\boldsymbol{T}_{\mathbf{2}}$ & $\boldsymbol{T}_{\mathbf{3}}$ & $\boldsymbol{T}_{\mathbf{4}}$ & $\boldsymbol{T}_{\mathrm{d}, \text { inflection }}$ \\
\hline Initial mass & Final mass & $m_{\mathrm{i}}-m_{\mathrm{f}}$ & $\begin{array}{l}\text { Beginning of } \\
\text { the mass loss }\end{array}$ & $\begin{array}{l}\text { Onset beginning } \\
\text { of mass loss }\end{array}$ & $\begin{array}{l}\text { End set of the } \\
\text { mass loss }\end{array}$ & $\begin{array}{l}\text { End of the } \\
\text { mass loss }\end{array}$ & $\mathrm{d} m / \mathrm{d} T=0$ \\
\hline
\end{tabular}

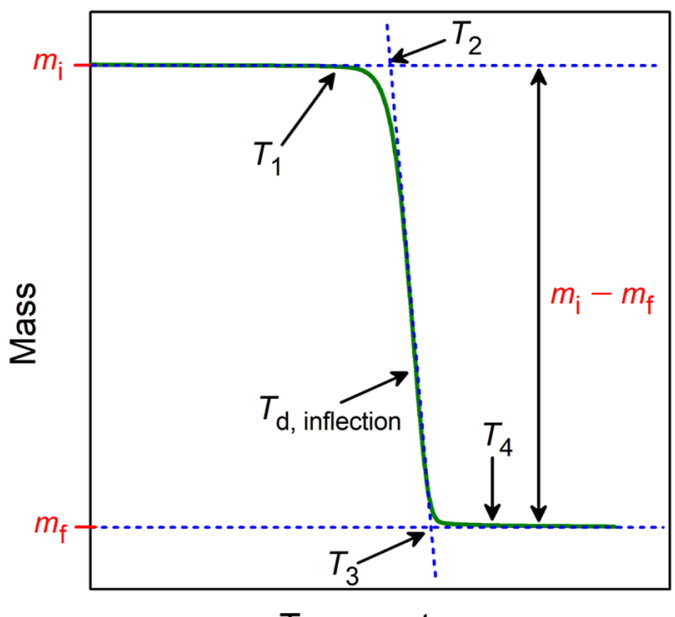

Temperature

Figure 12: Quantities available from a thermogravimetric curve. 


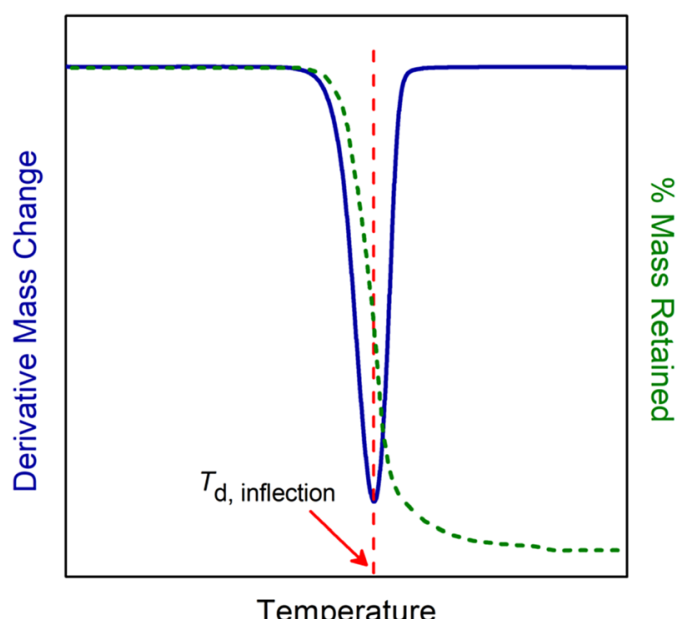

Figure 13: Shape of a derivative thermogravimetric analysis (DTGA) curve.

Using the example of Signal 1, it is possible to extract the information reported in Table 1 and which are also indicated in Figure 12.

It is possible to obtain the eight parameters for each degradation step. The determination of quantities $m_{\mathrm{i}}$, $m_{\mathrm{f}}$ and $\Delta m$ are rather easy, but relatively not too easy for quantities $T_{1}, T_{2}, T_{3}$ and $T_{4}$ as these quantities depend greatly on the quality of the signal. Alternatively, it is better to use the derivative $\mathrm{d} m / \mathrm{d} T$ curve to estimate the characteristic temperatures of the degradation process at its extremum, known as inflection point $\left(T_{\mathrm{d}}\right.$, inflection $)$. The derivative curve obtained from a single step decomposition process is displayed in Figure 13. Example of TGA analysis where $T_{\mathrm{d}}$, inflection and the temperature onset beginning of mass loss ( $\left.T_{d \text {, onset }}\right)$ for poly(ethylene oxide)/natural rubber-graft-poly(methyl methacrylate) (PEO/NR-g-PMMA) binary blends (Zainal, Chan, \& Ali, 2017) are listed in Table 2.

Example of bad baselines are presented in Figure 14. In Figure 14(a), the first baseline shows a typical effect of a gas purge problem (e.g. the chimney of the evacuated gas is more or less obtruded). The second baseline is due to the gas, which is firstly quasi blocked in the chimney, and at a certain temperature the chimney is suddenly open. Cleaning procedures of the gas purge and gas evacuation equipment are needed to solve these problems. Baseline 3 happens when there is a defect in the thermocouple welding or the sensor. In this case, the measurement has to stop immediately, and repair is needed.

Example 1 in Figure 14(b) shows a typical bad sample signal when the sample is a small size powder form which makes the particles easily to be extracted from the oven and then drop back into the oven during heating. Whereas Example 2 is observed when the powder drops outside of the oven.

Knowledge of thermal stability and degradation mechanism of material is important. For example, data of thermal stability and degradation mechanism of conducting polymers must be required in order to know the optimum performance of the polymers to be used in specific application at certain temperature as well as to avoid any polymer degradation. This is because, due to the loss of dopant and conductivity at high temperature, the use of conducting polymers in electronic devices, solid state batteries, chemical sensors, etc., has

Table 2: $T_{d}$, onset and $T_{\mathrm{d}}$, inflection of PEO/NR- $g$-PMMA blends.

\begin{tabular}{lrr}
\hline Blend composition $\left(\boldsymbol{W}_{\text {PEO }}\right)$ & $\boldsymbol{T}_{\boldsymbol{d} \text {, onset }}\left({ }^{\circ} \mathrm{C}\right)$ & $\boldsymbol{T}_{\mathrm{d} \text {, inflection }}\left({ }^{\circ} \mathbf{C}\right)$ \\
\hline 1.0 & 374 & 392 \\
0.8 & 369 & 389 \\
0.6 & 368 & 390 \\
0.5 & 365 & 389 \\
0.4 & 362 & 389 \\
0.2 & 355 & 383 \\
0.0 & 350 & 380 \\
\hline
\end{tabular}




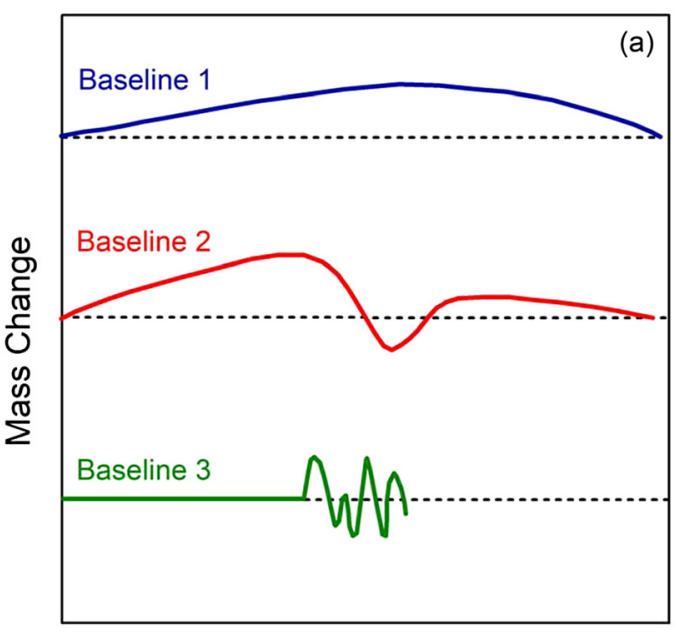

Temperature

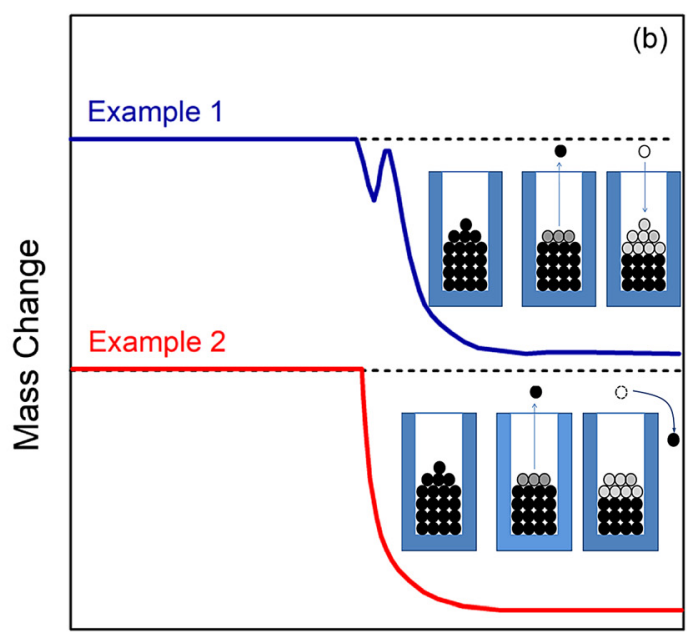

Temperature

Figure 14: Examples of (a) bad base lines and (b) bad sample signals.

been restricted (Chen, Dong, Li, \& Gao, 2009). Analysis from TGA should not only be restricted to different $T_{\mathrm{d}}$ values as in Table 2, but other important kinetic quantities, for example the $E_{\mathrm{a}}$, pre-exponential factor $(A)$ and order of degradation can be extracted. Many works have been reported on methods to determine these quantities (Carrasco, 1993; Freeman \& Carroll, 1958; Friedman, 1969; Kissinger, 1957; Yang, Fang, Liu, Liu, \& Zhou, 2000). These methods which are classified as integral, differential and special methods may involve a lot of experiments with tedious procedures and calculations. Hence, in this part, we discuss an alternative approach to determine the $E_{\mathrm{a}}$ quantity using the temperature-dependent of the rate of thermal degradation in terms of Hoffman's Arrhenius-like relationship (the step-by-step guides are provided in S4-Estimation of $E_{\mathrm{a}}$ ). In this relationship, the first derivatives of the mass retained (\%) versus reciprocal of temperature is used as written in Eq. (5);

$$
\text { |deriv. mass retained (\%) } \mid \alpha \exp \left(-\frac{E_{\mathrm{a}}}{R T}\right)
$$

where $R$ is the gas constant. The estimation of $E_{\mathrm{a}}$ quantity can be extracted from the slope of the semilogarithmic plots of Eq. (5) as shown in the linear region in Figure 15.

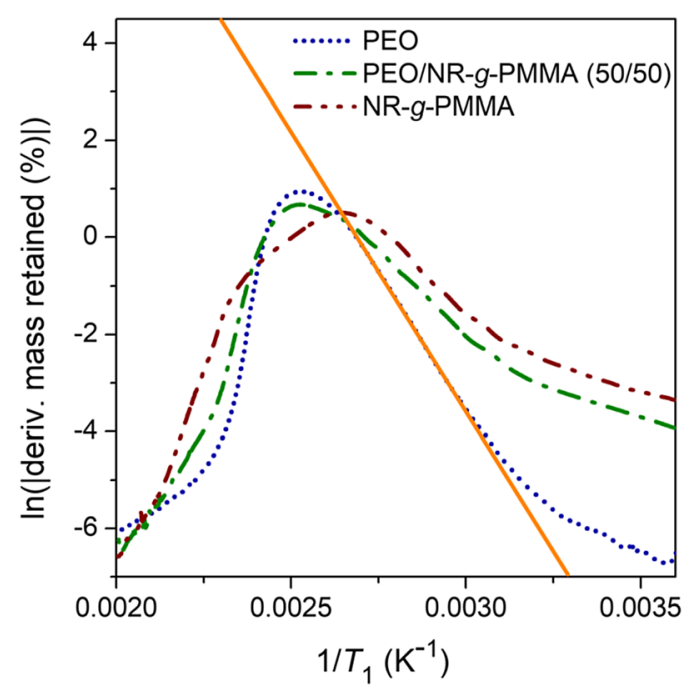

Figure 15: Plot of $\ln (\mid$ deriv. mass retained $\mid)$ against $1 / T_{1}$. Solid regression curve is after Eq. (5). Data is retrieved from (Zainal et al., 2017). 
Table 3: Activation energy of the rate of thermal degradation.

\begin{tabular}{lrrr}
\hline System & $\begin{array}{r}\text { Activation energy, } \\
\boldsymbol{E}_{\mathbf{a}}\left(\mathbf{k} \mathbf{~ m o l}^{\mathbf{- 1}} \mathbf{)}\right.\end{array}$ & $\boldsymbol{r}^{\mathbf{2}}$ & Refs. \\
\hline PEO & 59 & 0.99 & Zainal et al. (2017) \\
NR-g-PMMA & 39 & 0.98 & Zainal et al. (2017) \\
Poly(methyl acrylate) $(\mathrm{PMA})$ & 31 & 0.99 & Halim et al. (2016) \\
PEO/NR-g-PMMA $(50 / 50)(\mathrm{m} / \mathrm{m})$ & 45 & 0.98 & Zainal et al. (2017) \\
PEO/PMA $(50 / 50)(\mathrm{m} / \mathrm{m})$ & 40 & 0.99 & Halim et al. (2016) \\
\hline
\end{tabular}

Table 3 lists the $E_{\mathrm{a}}$ quantities for different systems estimated using the Hoffman's Arrhenius-like relationship, retrieved from (Halim, Chan, \& Sim, 2016; Zainal et al., 2017).

\section{Conclusions}

The basic overview of thermal analysis was presented, which covers the instrumentation of DSC and TGA, stepby-step guides for the estimation of $T_{\mathrm{g}}$ value, explanation on the estimation of quantity $E_{\mathrm{a}}$ based on Hoffman's Arrhenius-like relationship as well as exercises for the estimation of $T_{\mathrm{g}}$ value. This initiative will enhance the understanding and suitable for teachers and course instructors to coach the university students on how to perform good measurements together with correct data acquisition.

Acknowledgments: The authors would like to thank Ms. Norsyazlin Abd Rashid for providing the figures in the supplementary files (S2 and S3).

Author contribution: All the authors have accepted responsibility for the entire content of this submitted manuscript and approved submission.

Research funding: None declared.

Conflict of interest statement: The authors declare no conflicts of interest regarding this article.

\section{Annexe 1}

\section{Peer Reviewed Journals}

\section{Journal of Thermal Analysis and Calorimetry}

(JTAC) is a fully peer-reviewed, publishes papers covering all aspects of thermal analysis, calorimetry, and experimental thermodynamics.

Editor-in-Chief, I. M. Szilágyi

Published by Springer

\section{Thermochimica Acta}

An International Journal about all aspects of Thermoanalytical and Calorimetric Methods and their Application to Experimental Chemistry, Physics, Biology and Engineering.

Editors: S. Vyazovkin, N. Koga, and R. Androsch

Published by Elsevier 


\section{Books}

Handbook of Differential Thermal Analysis

W. J. Smothers and Yao Chiang

SBN-13/EAN: 9780820601298, ISBN: 0820601292

Published by Chemical Publishing, 1966

Applications of Differential Thermal Analysis in Cement chemistry

V. S. Ramachandran and D. Phil

ISBN-13: 9780820600246, ISBN-10 :0820600245

Published by Chemical Publishing Company, Incorporated, 1969

Thermal Analysis Part D, Volume XII D: Thermophysical Properties of Solids. Their Measurement and Theoretical Thermal Analysis (Comprehensive Analytical Chemistry)

J. Sestak

ISBN: 0444996532

Published by Elsevier Science, 1984

Thermal Analysis of Materials (Materials Engineering) First Edition

R. Speyer

ISBN-13: 978-0824789633, ISBN-10: 0824789636

Published by CRC Press, 1993

Calorimetry and Thermal Analysis of Polymers

V. B. F. Mathot and L. Benoist

ISBN-13: 978-1569901267, ISBN-10: 1569901260

Published by Hanser Publishers, 1994

Thermal Methods of Analysis: Principles, Applications and Problems

P. J. Haines

ISBN-13: 978-0751400502 and ISBN-10: 0751400505

Published by Springer, 1995

\section{Thermal Data for Natural and Synthetic Fuels}

S. Gaur and T. B. Reed

ISBN-13: 9780824700706, ISBN-10: 0824700708

Published by CRC Press, 1998

\section{Handbook of thermal Analysis and calorimetry}

Series editor P. K. Gallaher

Published by Elsevier

Volume 1, 1998, Editor: Michael Brown Handbook of Thermal Analysis and Calorimetry

Volume 2, 2002, Editors: M. E. Brown, P. K. Gallagher Application to Inorganic and Miscellaneous Materials Volume 3, 2002, Editor: S. Z. D. Cheng, Application to Polymers and Plastics

Volume 4, 1999; Editor: R. B. Kemp, From Macromolecules to Man

Volume 5, 2007, Editor: M. E. Brown, Recent Advances, Techniques and Application

Volume 6, 2018, Editors: S. Vyazovkin, N. Koga, C. Schick Recent Advances, Techniques and Applications 
Thermal Analysis: Fundamentals and Applications to Polymer Science (Second Edition)

T. Hatakeyama and F. X. Quinn

ISBN-13: 978-0471983620, ISBN-10: 9780471983620

Published by Wiley, 1999

Handbook of Thermal Analysis

T. Hatakeyama and Zhenhai Liu

ISBN: 0471983632

Published by Wiley, 1999

Characterisation of Polymers by Thermal Analysis (First Edition)

W. M. Groenewoud

ISBN: 9780444506047

Published by Elsevier Science, 2001

Principles of Thermal Analysis and Calorimetry

P. J. Haines

ISBN: 1788018133, 9781788018135

Published by RSC Paperbacks Publishing, 2002

Thermal Analysis of Plastics: Theory and Practice

G.W. Ehrenstein, G. Riedel, and P. Trawiel

ISBN-13:9781569903629

Published by Hanser Publications, 2004

Thermal Analysis Techniques and Applications

M. E. Brown

ISBN: 1-4020-0472-9

Published by Kluwer Academic, 2004

Thermal Analysis of Polymeric Materials

B. Wunderlich

ISBN: 3540236295,9783540236290

Published by Springer Berlin, 2005

Thermal Analysis of Pharmaceutical

D. Q. M. Craig and M. Reading

ISBN-13: 9780824758141

Published by CRC Press, Taylor \& Francis group, 2006

Principles and Applications of Thermal Analysis

P. Gabbott (Editor)

ISBN-13: 978-1-405-13171-1

Published by Wiley-Blackwell, 2007

Thermal Decomposition of Solids and Melt

B. V. L'vov

ISBN: 978-1-4020-5671-0

Published by Springer, 2007 
Thermal Analysis for Polymers Fundamentals and Applications (First Edition)

J. D. Menczel and R. B. Prime

ISBN-13: 9780471769170 and ISBN-10: 0471769177

Published by Wiley, 2009

Thermal Properties of Green Polymers and Biocomposites

T. Hatakeyama and H. Hatakeyama

ISBN-13: 9789048165421 and ISBN-10: 9048165423

Published by Springer, 2010

Sample Controlled Thermal Analysis: Origin, Goals, Multiple Forms, Applications and Future

O. Toft Sorensen and J. Rouquerol

ISBN-13: 9781441952493

Published by Springer US, 2011

Thermal Analysis

B. Wunderlich

ISBN: 9780323139670

Published by Academic Press, 2012

Thermal analysis of Micro, Nano- and Non-Crystalline Materials - Transformation, Crystallization, Kinetics and Thermodynamics

J. Sesták and P. Simon

ISBN: 978-90-481-3149-5

Published by Springer, 2012

Thermal Methods of Polymer Analysis

T. R. Crompton

ISBN-13: 9781847356628 and ISBN-10: 1847356621

Published by Smithers Rapra Publishing, 2013

Who is Who in Thermal Analysis and Calorimetry (Hot Topics in Thermal Analysis and Calorimetry) I. M. Szilagyi and G. Liptay

ISBN-13: 9783319094854 and ISBN-10: 3319094858

Published by Springer, 2014

Differential Thermal Analysis, Application and Results in Mineralogy

W. S. Kloss

ISBN-13: 9783642659515

Published by Springer, 2015

Principles of Thermal Analysis and Calorimetry

S. Gaisford, V. Kett and P. Haines

ISBN: 9781782620518

Published by RSC, 2016

Calorimetry and Thermal Methods in Catalysis

A. Auroux

ISBN-13: 9783662519264

Published by Springer, 2016 


\section{From Macro to Micro, Highlighting Thermodynamics, Kinetics and Nanomaterials}

J. Sestak, P. Hubik and J. J. Mares

ISBN-13: 9783319458977

Published by Springer, 2017

\section{Thermal Analysis in Practice}

M. Wagner

ISBN: 978-1-56990-643-9

Published by Hanser Publication, 2018

\section{Thermal Analysis of Textiles and Fibers}

M. Jaffe and J. D. Mencel

ISBN: 978-0-08-100572-9

Published by Woodhead Elsevier, 2020

\section{References}

Carrasco, F. (1993). The evaluation of kinetic parameters from thermogravimetric data: Comparison between established methods and the general analytical equation. Thermochimica Acta, 213(C), 115-134.

Chen, T., Dong, C., Li, X., \& Gao, J. (2009). Thermal degradation mechanism of dodecylbenzene sulfonic acid-hydrochloric acid codoped polyaniline. Polymer Degradation and Stability, 94(10), 1788-1794.

Freeman, E. S., \& Carroll, B. (1958). The application of thermoanalytical techniques to reaction kinetics: The thermogravimetric evaluation of the kinetics of the decomposition of calcium oxalate monohydrate. The Journal of Physical Chemistry, 62(4), 394-397.

Friedman, H. L. (1969). New methods for evaluating kinetic parameters from thermal analysis data. Journal of Polymer Science Part B: Polymer Letters, 7(1), 41-46.

Halim, S. I. A., Chan, C. H., \& Sim, L. H. (2016). Thermal properties and intermolecular interaction of blends of poly (ethylene oxide) and poly (methyl acrylate). Macromolecular Symposia, 365(1), 95-103.

Halim, S. I. A., Chan, C. H., \& Kammer, H.-W. (2019). About glass transition in polymer-salt mixtures. Polymer Testing, $79,105994$.

Hatakeyama, T., \& Quinn, F. X. (1999). Thermal analysis: fundamentals and applications to polymer science (2nd ed.). Sussex: John Wiley \& Sons.

Kissinger, H. E. (1957). Reaction kinetics in differential thermal analysis. Analytical Chemistry, 29(11), 1702-1706.

Loft, B. C. (1975). Applications of thermal analysis to polymers. Journal of Polymer Science: Polymer Symposia 49(1), 127-139.

Saiter, J. M., Negahban, M., Claro, P. D. S., Delabare, P., \& Garda, M. R. (2008). Quantitative and transient DSC measurements. I-heat capacity and glass transition. Journal of Materials Education, 30(1), 51.

Schick, C. (2009). Differential scanning calorimetry (DSC) of semicrystalline polymers. Analytical and Bioanalytical Chemistry, 395(6), 1589-1611.

Thermal Analysis. (n.d.a). Differential scanning calorimetry. Retrieved from itlinc.com/thermogravimetric-analysis/.

Thermal Analysis. (n.d.b). Thermogravimetric analysis. Retrieved from itlinc.com/thermogravimetric-analysis/.

Wendlandt, W. W. (1986). Thermal analysis (3rd ed.). New York: John Wiley \& Sons, Inc.

Wunderlich, B. (1994). Nature of the glass transition and its determination by thermal analysis. Philadelphia, PA 19103, USA: ASTM Special Technical Publication.

Wunderlich, B. (2006). The glass transition of polymer crystals. Thermochimica Acta, 446, 128-134.

Wunderlich, B. (2007). Thermal analysis of macromolecules: A personal review. Journal of Thermal Analysis and Calorimetry, 89, 321-356.

Yang, C., Fang, Z., Liu, J., Liu, W., \& Zhou, H. (2000). A study on the kinetics of thermal decomposition of polyaniline. Thermochimica Acta, 352-353, 159-164.

Zainal, N. F. A., Chan, C. H., \& Ali, A. M. M. (2017). Compatibility and thermal properties of poly(ethylene oxide)/natural rubber-graftpoly(methyl methacrylate) blends. In Applied chemistry and chemical engineering, Vol. 4: Experimental techniques and methodical developments (1st ed., pp. 55-76). New York: Apple Academic Press.book-chapter.

Supplementary Material: Four supplementary files (i.e. S1-Notes for Course Instructor, S2-Examples to Estimate $T_{\mathrm{g}}$, S3-Exercise for Students and S4-Estimation of $E_{\mathrm{a}}$ ) are provided separately online for educational purposes (https://doi.org/10.1515/cti-20200010). 